\title{
High Strength and High Modulus Carbon Fibers
}

Han Gi Chae ${ }^{1}$, Bradley A. Newcomb ${ }^{1}$, Prabhakar V. Gulgunje ${ }^{1}$, Yaodong Liu ${ }^{1}$, Kishor K. Gupta $^{1}$, Manjeshwar G. Kamath ${ }^{1}$, Kevin M. Lyons ${ }^{1}$, Sushanta Ghoshal ${ }^{1}$, Chandrani Pramanik ${ }^{1}$, Lucille Giannuzzi $^{2}$, Korhan Sahin ${ }^{3}$, Ioannis Chasiotis ${ }^{3}$, Satish Kumar ${ }^{1, *}$

${ }^{1}$ School of Materials Science and Engineering, Georgia Institute of Technology, 801 Ferst Dr. NW, Atlanta, GA 30332, USA.

${ }^{2}$ L.A. Giannuzzi \& Associates LLC, 12580 Walden Run Dr., Fort Myers, FL 33913, USA.

${ }^{3}$ Department of Aerospace Engineering, University of Illinois at Urbana Champaign, 104 S. Wright St, Urbana, IL 61801, USA.

\begin{abstract}
Carbon fibers have been processed from gel spun polyacrylonitrile copolymer on a continuous carbonization line at Georgia Tech (GT) with a tensile strength in the range of 5.5 to $5.8 \mathrm{GPa}$, and tensile modulus in the range of 354 to $375 \mathrm{GPa}$. This combination of strength and modulus is the highest for any continuous fiber reported to date, and the gel spinning route provides a pathway for further improvements in strength and modulus for mass production of carbon fibers. At short gauge length, fiber tensile strength was as high as $12.1 \mathrm{GPa}$, which is the highest value ever reported for a PAN based carbon fiber. Structure analysis shows random flaws of about $2 \mathrm{~nm}$ size, which results in intrinsic tensile strength of higher than $20 \mathrm{GPa}$. Inter-planar turbostratic graphite shear modulus in high strength carbon fibers is $30 \mathrm{GPa}$, while in graphite the corresponding value is only $4 \mathrm{GPa}$.
\end{abstract}

\footnotetext{
* Corresponding author, Tel: +1-404-894-7550; fax: +1-404-894-8780. E-mail: satish.kumar@mse.gatech.edu (Satish Kumar)
} 


\section{Introduction}

Polyacrylonitrile (PAN) polymer [1] was commercialized by the DuPont Company in 1950 and is the only precursor material from which currently high strength carbon fibers can be processed [2-4]. These PAN based carbon fibers are now being used for significant structural applications in aerospace industry (e.g. in Boeing 787), for power generation (wind mill blades), and are increasingly being used in automobiles. Although carbon filaments were first used in light bulbs in late nineteenth century, the research in modern carbon fibers started in 1959 in Japan and a key processing innovation occurred in England in 1964 resulting in high strength fibers. Following these developments, PAN based commercial T300 carbon fiber was introduced by the Toray Company of Japan in 1971 with a tensile strength of $2.5 \mathrm{GPa}$. Through material and process optimization, by 1980, the tensile strength of T300 carbon fiber was improved to 3.5 GPa [5]. Currently, a widely used PAN based carbon fiber in aerospace industry, the IM7, has a tensile strength of 5.6 GPa and tensile modulus of $276 \mathrm{GPa}$ [6]. PAN based carbon fiber (T1100G) with a tensile strength of $6.6 \mathrm{GPa}$ and tensile modulus of $324 \mathrm{GPa}$ was recently commercialized [7]. After more than 50 years of development, the tensile strength of high strength PAN based carbon fibers is still less than $10 \%$ of the theoretical strength of the carboncarbon bond [8,9], and about $30 \%$ of the theoretical modulus [10]. On the other hand, continuous pitch based carbon fibers can be manufactured with modulus as high as $965 \mathrm{GPa}$ (>90\% of the theoretical modulus). However, these high modulus pitch based carbon fibers have relatively low tensile strength $(3.1 \mathrm{GPa})$, resulting from large graphitic grain boundaries and relatively low inter-planar shear modulus. Although it is possible to process PAN based carbon fibers with tensile modulus approaching $600 \mathrm{GPa}$ (which is $57 \%$ of the theoretical value for graphite) via high temperature carbonization, this high tensile modulus is achieved at the expense of tensile strength (Fig. 1). Clearly, there is room and need to increase the strength of carbon fibers while also increasing their modulus.

Man-made polymeric fibers are processed by melt or solution spinning [11]. While PAN can be melt spun, currently all commercial PAN fiber production is based on solution spinning. Gel spinning [12] is used for making high strength and high modulus polymeric fibers and can lead to fewer entanglements in the fiber than in the melt and conventional solution spun fiber of the same molecular weight. Through gel spinning, high molecular weight polymer solutions can be spun with higher molecular alignment than what can be achieved by conventional solution 
spinning, resulting in higher modulus of the carbonized fiber. However, to date carbonization of gel spun PAN fibers has been carried out as a batch process [13-15], and there are no reports of gel spun fiber carbonization in a continuous process. It has been hypothesized that the continuous carbonization of gel spun PAN will result in a combination of higher strength and higher modulus carbon fibers compared to the conventional solution spun PAN based carbon fibers.

\section{Experimental}

\subsection{Fiber Processing}

The polymer used in the current study was poly(acrylonitrile-co-methacrylic acid) (PANco-MAA) copolymer with a viscosity average molecular weight of 513,000 g/mol (Japan Exlan Company, Osaka, Japan). The polymer was dissolved in $N, N$-dimethylformamide (DMF) at 90 ${ }^{\circ} \mathrm{C}$ at a concentration of $10.5 \mathrm{~g} / \mathrm{dl}$. The prepared solution was spun using a spinning machine equipped with a 100-hole spinneret (hole diameter of $200 \mu \mathrm{m}$ ). The fiber was spun into a methanol bath maintained at $-50^{\circ} \mathrm{C}$ using an air gap of about $2 \mathrm{~cm}$. The as-spun draw ratio was 3 and the post-spin draw ratio was 8.2 (total draw ratio was 24.6). Post-spin drawing was conducted via multi-step drawing at the drawing temperature as high as $180{ }^{\circ} \mathrm{C}$. The tensile properties and structural parameters of the precursor fiber are listed in Table 1. It is noted that the tensile modulus of this gel spun PAN precursor is $20.7 \mathrm{GPa}$. This value is significantly higher than the modulus value achieved in the solution spun PAN fiber, which is typically in the range of 7 to $14 \mathrm{GPa}[16,17]$. Higher tensile modulus in the gel spun fiber is a result of significantly higher draw ratios achieved in gel spinning than in solution spinning [13, 16, 18]. The precursor

fiber tow was stabilized and carbonized using the laboratory scale continuous carbonization facility at GT (Supplementary Fig. 1). The stabilization and carbonization temperatures were as high as $250^{\circ} \mathrm{C}$ and $1450^{\circ} \mathrm{C}$, respectively. 
Table 1. Tensile and structural properties of the GT PAN precursor fiber.

\begin{tabular}{|l|l|c|}
\hline \multicolumn{2}{|l|}{$\mid$} & GT PAN precursor fiber \\
\hline Effective diameter $(\mu \mathrm{m})$ & $11.0 \pm 0.8$ \\
\hline \multirow{2}{*}{ Density $\left(\mathrm{g} / \mathrm{cm}^{3}\right)$} & 1.207 \\
\hline \multirow{2}{*}{$\begin{array}{l}\text { Tensile } \\
\text { properties }\end{array}$} & Strength $(\mathrm{GPa})$ & $1.0 \pm 0.1$ \\
\cline { 2 - 3 } & Modulus $(\mathrm{GPa})$ & $20.7 \pm 1.1$ \\
\cline { 2 - 3 } & Elongation at break $(\%)$ & $9.4 \pm 1.5$ \\
\hline \multirow{3}{*}{$\begin{array}{l}\text { WAXD } \\
\text { analysis }\end{array}$} & $d$-spacing $(200,110)(\mathrm{nm})$ & 0.527 \\
\cline { 2 - 3 } & Crystallinity $(\%)$ & 64 \\
\cline { 2 - 3 } & Crystal size $\mathrm{L}_{(200,110)}(\mathrm{nm})$ & 15.7 \\
\cline { 2 - 4 } & FWHM $_{\text {azi, (200,110) }}($ degrees $)$ & 6.7 \\
\hline
\end{tabular}

${ }^{\mathrm{a}}$ Tensile properties were measured for $25.4 \mathrm{~mm}$ gauge length at a strain rate of $1 \% / \mathrm{s}$.

\subsection{Characterization}

Tensile tests of the precursor and the carbon fibers were performed with a single filament tensile testing machine (FAVIMAT+, Measured Solutions Inc.) as described elsewhere [19]. The linear densities of the fibers were measured by a vibroscope prior to tensile testing for a fiber gauge length of $25.4 \mathrm{~mm}$. The measured linear density was converted to an effective diameter using the measured bulk density of the precursor and carbon fibers, respectively. The bulk density of the fibers was measured using a pycnometer (AccuPyc II 1340, Micromeritics, Inc). Tensile fractured cross-sections were imaged using a Zeiss Ultra 60 FE-SEM at an accelerating voltage of $5 \mathrm{kV}$ without Au-Pd coating. Tensile testing was also done at $100 \mu \mathrm{m}$ gauge length using a custom designed apparatus for microscale tensile testing. At short gauge lengths, the tensile strength for each fiber was determined by measuring the cross-sectional area of the fractured fiber SEM image.

The structural characteristics of the precursor and carbonized fibers were studied using wide-angle x-ray diffraction (WAXD). WAXD patterns were collected on a Rigaku micromax$002\left(\mathrm{CuK}_{\alpha}, \lambda=0.1542 \mathrm{~nm}\right)$ equipped with Rigaku R-axis IV++ detector. The collected 2D patterns were analyzed using Area Max v2 and peak fitting was performed using JADE 9.1.5. Raman spectra were collected on a Horiba Scientific Xplora confocal microRaman system (laser wavelength $=785 \mathrm{~nm}$ ). For transmission electron microscopy, carbon fiber samples were mounted on a copper 3 post Omniprobe lift-out grid (Electron Microscopy Sciences, Inc.) using Epo-Tek 353ND epoxy (Gatan, Inc.) for transverse cross-sectioning. After curing the epoxy at 60 ${ }^{\circ} \mathrm{C}$ for 2 days, the fiber was thinned using a FEI Nova Nanolab 200 FIB/SEM. The carbon fiber 
was first protected with a platinum layer. Then, ion beam milling at $30 \mathrm{keV}$ was done followed by final milling at $5 \mathrm{keV}$ until electron transparency was achieved. TEM imaging was performed on a Tecnai TF30 (FEI, Co.) at an accelerating voltage of $80 \mathrm{keV}$. The thermal stability was studied on a Q500 TGA (TA Instruments) by heating $0.85 \pm 0.08 \mathrm{mg}$ of fiber from $30{ }^{\circ} \mathrm{C}$ to 1000 ${ }^{\circ} \mathrm{C}$ at a heating rate of $10{ }^{\circ} \mathrm{C} / \mathrm{min}$ using an air flow rate of $25 \mathrm{~mL} / \mathrm{min}$.

\section{Results and Discussion}

In this work, carbon fibers have been produced in multiple gel spinning runs of precursor fibers and carbonization with average tensile strength values in the range of 5.5 to $5.8 \mathrm{GPa}$ and tensile modulus in the range of 354 to $375 \mathrm{GPa}$ (Fig. 1 and Table 2). There are no other fibers with this combination of tensile strength and modulus, and their modulus is $25-36 \%$ higher than that for the IM7 carbon fiber. Normally, an increase in the carbon fiber tensile modulus is accompanied by a decrease in tensile strength. For example, the tensile strength of current PAN based commercial fiber (M40JB) with a modulus of $377 \mathrm{GPa}$ is only $4.4 \mathrm{GPa}$ (Fig.1). However, the higher tensile modulus in the current gel spun PAN based carbon fiber as compared to the IM7 carbon fiber is without any loss in tensile strength (Fig.1, Table 2).

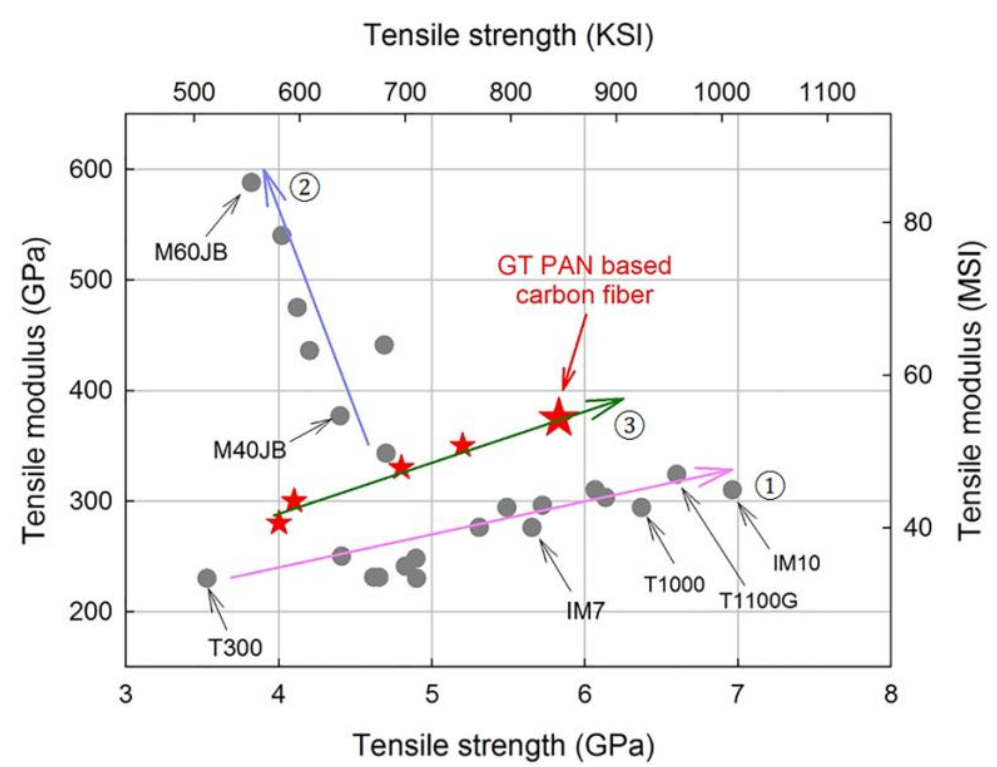

Fig. 1 - Tensile strength versus tensile modulus of various PAN based carbon fibers. Circles represent the tensile properties of commercial PAN based carbon fibers. Stars represent the tensile strength and modulus of the GT PAN based carbon fibers. Trend lines (1) and (2) represent trajectory of the developments in the high strength and high modulus solution spun PAN based carbon fibers, respectively over the last 30 years. Trend line (3) represents the development trajectory in gel spun PAN based carbon fiber over the last 3 years. 
Table 2. Properties and structural parameters of various carbon fibers.

\begin{tabular}{|l|l|c|c|c|c|}
\hline \multirow{2}{*}{} & \multicolumn{3}{|c|}{ PAN based carbon fibers } & $\begin{array}{c}\text { Pitch-based } \\
\text { carbon fiber }\end{array}$ \\
\cline { 3 - 6 } & GT carbon fiber & IM7 & T300 & K-1100 \\
\hline \multicolumn{2}{|l|}{ Cross-sectional area $(\mu \mathrm{m})^{2}$} & $19.6-21.2$ & $21.2[6]$ & $38.5[5]$ & $113.1[4]$ \\
\hline \multicolumn{2}{|l|}{ Density $\left(\mathrm{g} / \mathrm{cm}^{3}\right)$} & $1.77-1.79$ & $1.78[6]$ & $1.76[5]$ & $2.20[4]$ \\
\hline \multirow{2}{*}{$\begin{array}{l}\text { Tensile } \\
\text { properties }\end{array}$} & Strength $(\mathrm{GPa})$ & $5.5-5.8$ & $5.6[6]$ & $3.6[5]$ & $3.1[4]$ \\
\cline { 2 - 6 } & Modulus $(\mathrm{GPa})$ & $354-375$ & $276[6]$ & $230[5]$ & $965[4]$ \\
\hline $\begin{array}{l}\text { Oxidative thermal degradation } \\
\text { temperature }\left({ }^{\circ} \mathrm{C}\right)\end{array}$ & 815 & 714 & 771 & 877 \\
\hline \multirow{2}{*}{$\begin{array}{l}\text { WAXD } \\
\text { analysis* }\end{array}$} & $d_{002}(\mathrm{~nm})$ & 0.344 & 0.348 & 0.349 & 0.337 \\
\cline { 2 - 6 } & $L_{002}(\mathrm{~nm})$ & 1.9 & 1.6 & 1.4 & 26.6 \\
\cline { 2 - 6 } & $L_{10}(\mathrm{~nm})$ & 2.5 & 2.1 & 2.0 & 21.1 \\
\cline { 2 - 6 } & $\begin{array}{l}\mathrm{FWHM} \\
(\mathrm{degrees})\end{array}$ & 23.1 & 30.3 & 35.0 & $0.5-1.0[20]$ \\
\hline $\begin{array}{l}\text { Raman } \\
\text { intensity ratio }\end{array}$ & $\mathrm{I}_{\mathrm{G}} / \mathrm{I}_{\mathrm{D}}$ & 0.46 & 0.43 & 0.39 & 2.00 \\
\hline
\end{tabular}

$* d_{002}, L_{002}$, and $L_{10}$ are inter-planar graphitic spacing, crystal size perpendicular to (002), and crystal size within graphitic plane along the fiber axis, respectively.

Spools of the gel spun PAN precursor and carbon fibers produced in this study are shown in Fig. 2a. Notably, the high strength and high modulus carbon fiber processed via gel spinning route has a non-circular cross-section (Fig. 2b,c and Supplementary Fig. 2), while the commercial high strength, high modulus carbon fibers (cross-sections of IM7 and T1000 are shown in Fig. 2d,e) have near perfect circular cross-sections. Oxygen diffusion from the fiber surface to the core plays an important role in stabilizing the fiber structure [21]. Due to this oxygen diffusion, a circular fiber would result in a more homogeneous structure than a noncircular fiber. Therefore, it is expected that the tensile strength of the gel spun PAN based carbon fiber will increase further with an increase in fiber circularity, provided that the internal microand nano-structure of the fiber is not negatively affected by enhanced circularity.

High resolution transmission electron microscopy (HRTEM) images of carbon fibers derived from gel spun PAN fibers showed well developed turbostratic graphitic structure (Fig. 
2f), with inhomogeneity at the level of 0.5 to $2 \mathrm{~nm}$ scale (e.g. features within circles in Fig. 2f). The IM7 (Fig. 2g) fiber has significantly more heterogeneous structure than the gel spun PAN carbon fiber. For comparison, among the three fibers, the T300 carbon fiber (Fig. 2h) shows the least developed turbostratic graphitic structure, as well as the most heterogeneity.
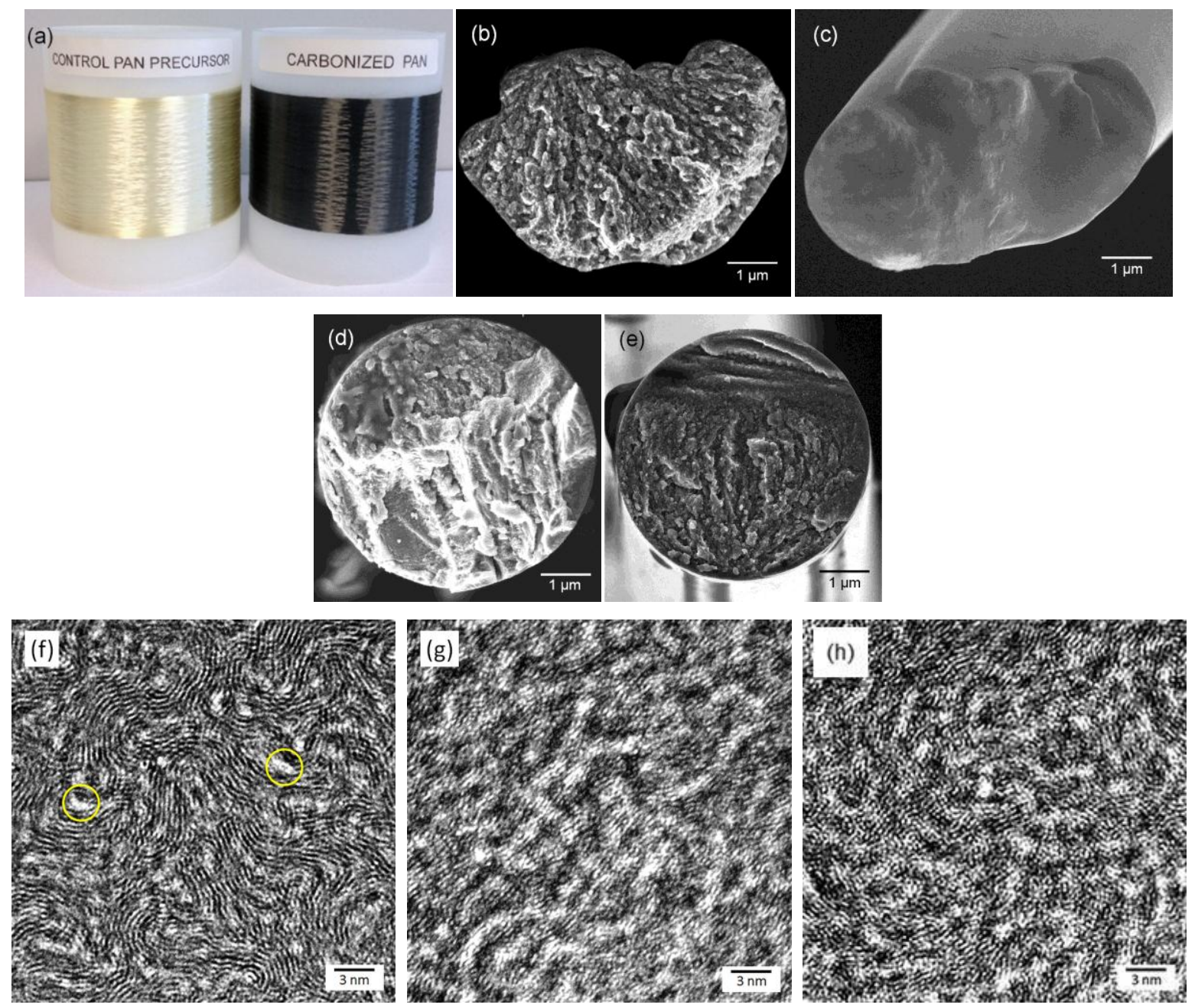

Fig. 2 - (a) Photograph of spools of the gel-spun GT PAN precursor fiber and the resulting carbon fiber, (b) SEM image of tensile fracture surface of the GT PAN based carbon fibers with tensile strength of $10.2 \mathrm{GPa}$ at $1 \mathrm{~mm}$ gauge length and (c) GT PAN based carbon fiber with a tensile strength of $12.1 \mathrm{GPa}$ at $100 \mu \mathrm{m}$ gauge length. For comparison, fiber cross-sectional images of (d) IM7 and (e) T1000 carbon fibers are also shown. IM7 fiber shown in (d) was tested at $1 \mathrm{~mm}$ gauge length and exhibited a tensile strength of $8.7 \mathrm{GPa}$. High resolution transmission electron micrographs of the (f) GT PAN based carbon fiber, (g) IM7 carbon fiber and (h) T300 carbon fiber. Regions within circles in (f) show areas of defects or heterogeneities that would decrease the fiber tensile strength. 
Tensile strength and tensile modulus data for the GT PAN based carbon fibers and for commercial carbon fibers (T300, IM7 and T1000) at various gauge lengths are given in Fig. 3, Fig. 4, and Supplementary Fig. 3. The highest tensile strength of GT PAN based carbon fibers of $25.4 \mathrm{~mm}$ gauge length was $8.5 \mathrm{GPa}$ (Fig. 4.e1), while that of the IM7 fiber was $6.9 \mathrm{GPa}$ (Fig. 4.d1). Tensile fracture cross-sectional images of fibers tested at $1 \mathrm{~mm}$ and $100 \mu \mathrm{m}$ gauge lengths exhibiting tensile strength values of 10.2 and $12.1 \mathrm{GPa}$ are shown in Fig. 2b,c (and Supplementary Fig. 2), respectively. The increase in tensile strength with decreasing gauge length is observed in many materials, as the probability of finding defects decreases with decreasing gauge length. The extrapolated intrinsic strength value for the GT PAN based carbon fiber is $20.3 \mathrm{GPa}$ (Fig. 3a). The intrinsic strength was determined based on extrapolation to $1 \mathrm{~nm}$, as this is the scale $(0.5$ to $\sim 2 \mathrm{~nm})$ at which the smallest size defects are present in the gel spun PAN based carbon fiber. About $0.5 \mathrm{~nm}$ size defects arise from the PAN polymer chain ends, while defects on the order of $2 \mathrm{~nm}$ can arise from polymer chain entanglements. Chain entanglements can be minimized but not fully eliminated in gel spinning as compared to conventional solution spinning. This is due to the fact that lower polymer concentration is used in gel spinning (10.5 g/dl in current study) as compared to solution spinning (typically $20 \mathrm{~g} / \mathrm{dl}$ ). Similarly, polymer chain ends can also not be fully eliminated, though the number of chain ends per unit volume will decrease with increasing polymer molecular weight. Thus tensile strength extrapolated to nano meter scale can be considered as the intrinsic strength of the PAN based carbon fiber. Using this intrinsic strength value and Griffith's equation [22, 23], a defect size of $2.4 \mathrm{~nm}$ is predicted (based on the modulus value of $375 \mathrm{GPa}$ and graphite fracture energy value of $4.2 \mathrm{~J} / \mathrm{m}^{2}$ ). This defect size is in agreement with the defect or the heterogeneity size observed by TEM (Fig. 2f). Plots of tensile strength as a function of defect size for different moduli carbon fibers are given in Fig. 3b,3c. Structural heterogeneity or defects govern the fiber tensile strength [24], and can arise from many factors including solution inhomogeneity, crystalline and amorphous morphology in the fiber, heterogeneity due to coagulation, and heterogeneity induced during stabilization and carbonization. At the molecular level, each end of the polymer molecule will result in a defect size of about $0.5 \mathrm{~nm}$. Therefore, the defect size of $2-3 \mathrm{~nm}$ would be created from $4-6$ entangled polymer molecules that would be responsible for the limiting fiber tensile strength of $20 \mathrm{GPa}$. 

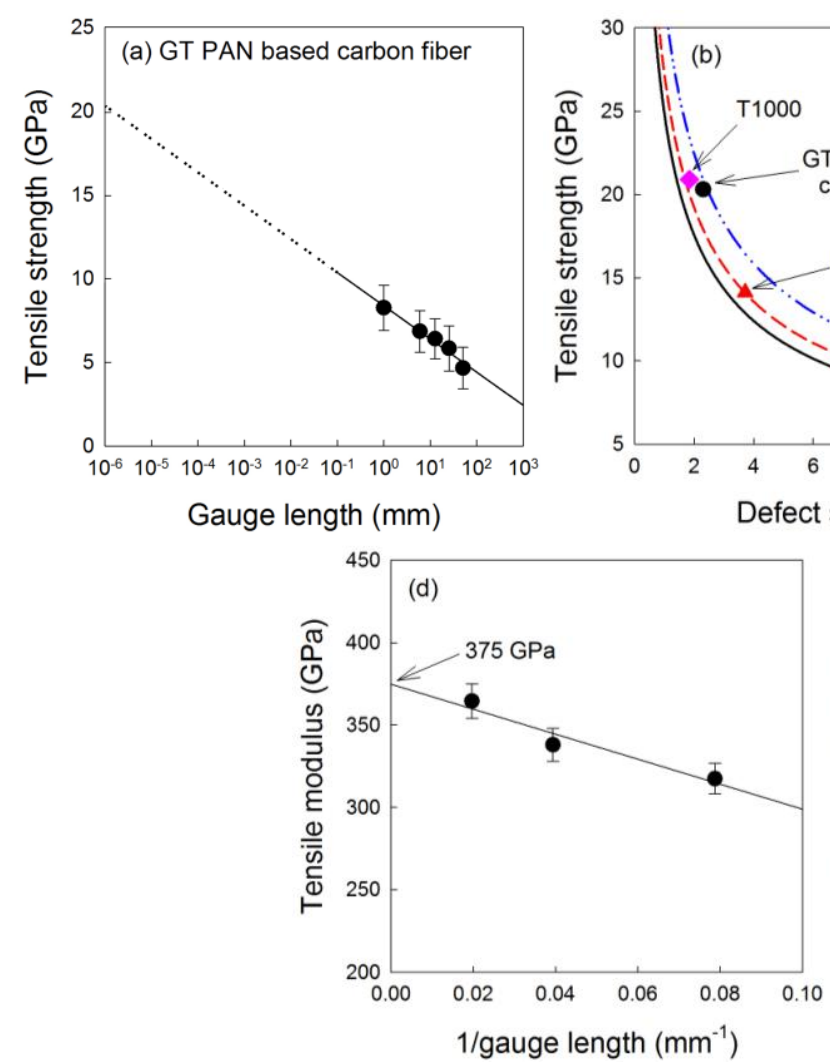
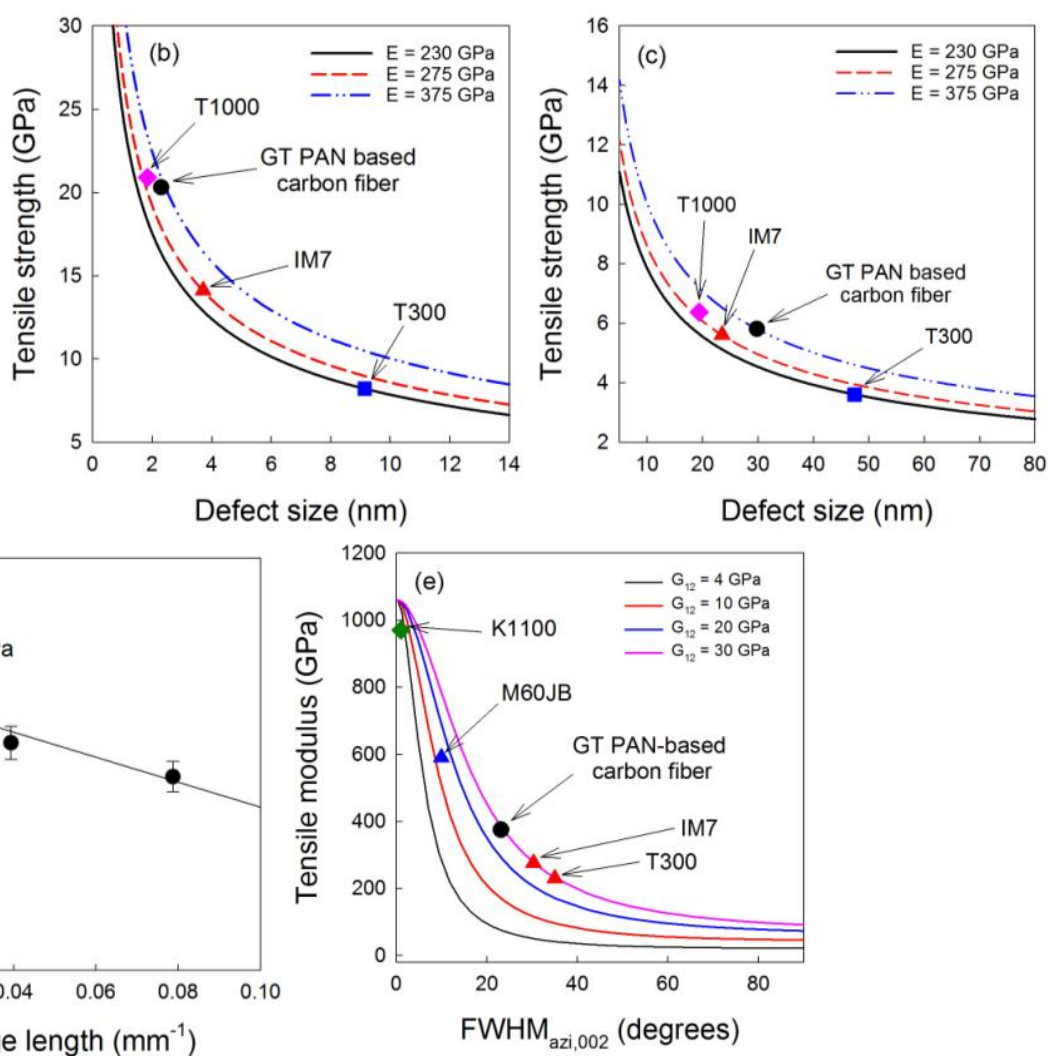

Fig. 3 - (a) Tensile strength of the GT PAN based carbon fibers at different gauge lengths; defect size calculated by Griffith equation [22, 23] for various carbon fibers based on (b) intrinsic strength values obtained by extrapolation to $1 \mathrm{~nm}$ gauge length, and (c) strength values tested at $25.4 \mathrm{~mm}$ gauge length; (d) tensile modulus of the GT PAN based carbon fiber as a function of inverse gauge length to obtain the compliance corrected tensile modulus; (e) theoretical tensile modulus $[10,25]$ as a function of full width at half maximum (FWHM) of the (002) azimuthal scans for various inter-planar shear modulus (G12) values. Data points for the selected carbon fibers are also shown.

The slope of the solution rheology plot Log G' vs Log G' is an indirect measure of the solution homogeneity [26], as well as polymer molecular entanglements. This slope value is 2 for a homogeneous solution. The plot of the dependence of the carbon fiber tensile strength on the slope of the Log G' vs Log G' plots of the corresponding solutions in Supplementary Fig. 4, shows increasing fiber strength with increasing slope of the Log G' vs Log G', plot. This is a rheological parameter at the molecular level that can be controlled and monitored to further increase the carbon fiber strength. 

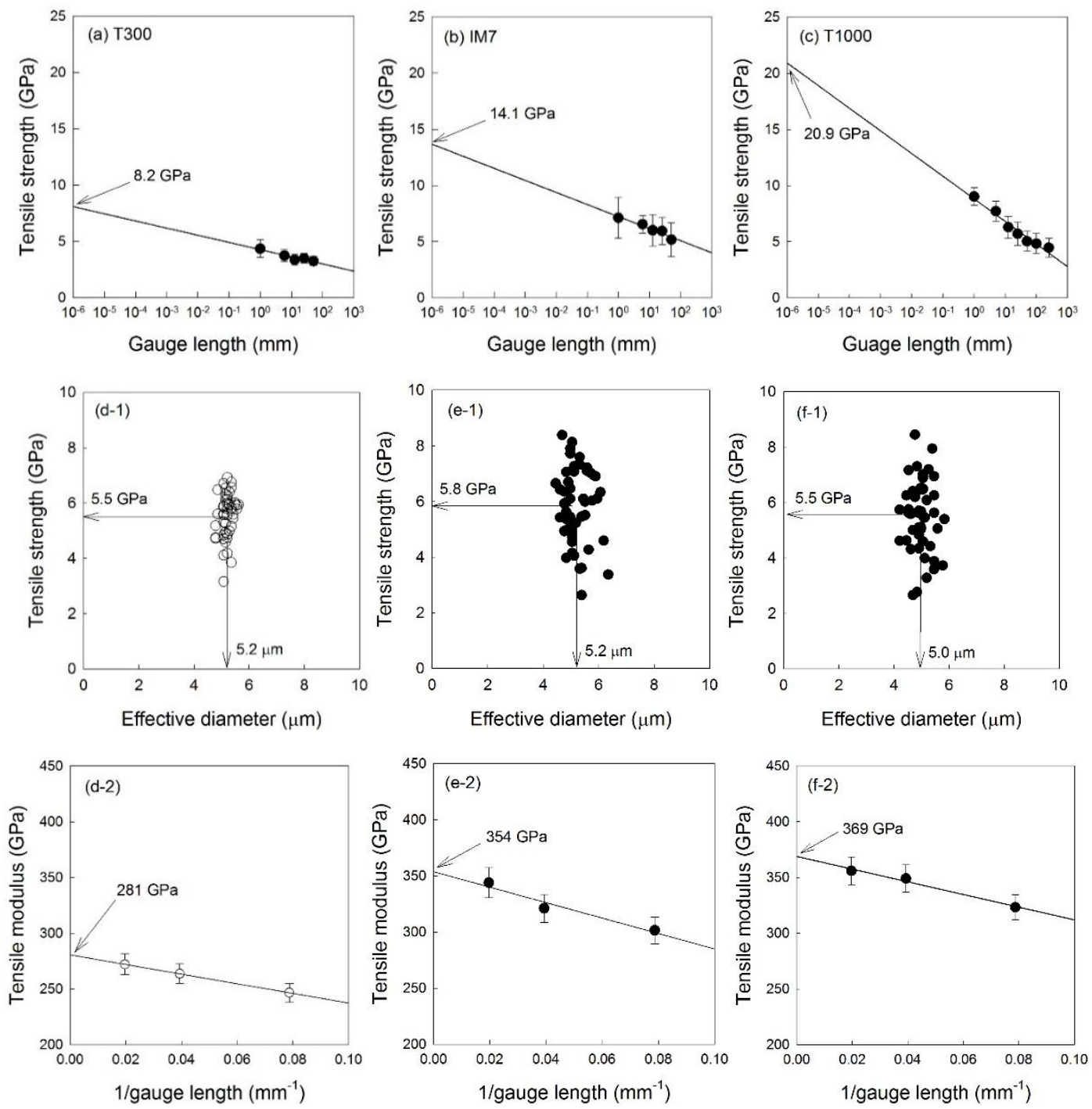

Fig. 4 - Tensile strengths of (a) T300, (b) IM7, and (c) T1000 [27] as a function of gauge length, estimating the intrinsic tensile strength of these fibers as $8.2 \mathrm{GPa}, 14.1 \mathrm{GPa}$, and $20.9 \mathrm{GPa}$, respectively; (d-1) tensile strength of individual testing results of IM7 carbon fiber at $25.4 \mathrm{~mm}$ gauge length; (d-2) tensile modulus as a function of inverse gauge length to obtain compliance corrected tensile modulus for the IM7 carbon fiber; (e-1, e-2, f-1, and f-2) are the tensile properties of the GT PAN based carbon fibers from two different fabrication runs under the same testing conditions. Data for a third run are given in Fig. 3a and 3d. The tensile modulus results are the average of about 50 tests. The tensile strength and tensile modulus values of IM7 fibers reported by the manufacturer are $5.6 \mathrm{GPa}$ and $276 \mathrm{GPa}$, respectively, and are within the experimental error of the values reported here based on single filament tests. Intrinsic strength of a Mitsubishi Rayon carbon fiber with a reported tensile strength of $4.7 \mathrm{GPa}$ and tensile modulus of $235 \mathrm{GPa}$ was determined to be $9.3 \mathrm{GPa}$ [28]. Considering that the reported tensile strength of this Mitsubishi Rayon carbon fiber is in between that of the T300 and IM7, and its intrinsic strength is also in between the values for these two fibers, this experimentally determined intrinsic strength value on the Mitsubishi Rayon carbon fiber provides validity for the extrapolated intrinsic strength values in Fig 3a, Fig. 4a, 4b, and 4c. 
A comparison of the structural parameters shows that the GT PAN based carbon fiber has smaller (002) d-spacing and larger crystal size perpendicular to the graphitic planes as well as in the plane along the fiber axis, and higher graphitic plane orientation (as measured by the full width at half maximum of the (002) azimuthal plane - that is $\mathrm{FWHM}_{\mathrm{azi}, 002}$ ), as compared to T300 and IM7 fibers (Table 2). Data in Table 2 also show that the GT PAN based carbon fiber has higher Raman $\mathrm{I}_{\mathrm{G}} / \mathrm{I}_{\mathrm{D}}$ ratio than that for T300 and IM7 fibers, which is consistent with the HRTEM images (Fig. 2f, $2 \mathrm{~g}$ and 2h). Notably, the GT PAN based carbon fiber exhibited about $100{ }^{\circ} \mathrm{C}$ higher thermal degradation temperature in air as compared to IM7 and about $40{ }^{\circ} \mathrm{C}$ higher as compared to T300 (Fig. 5). For comparison, the structure and property data for high modulus pitch based carbon fiber K1100 are also given in Table 2.

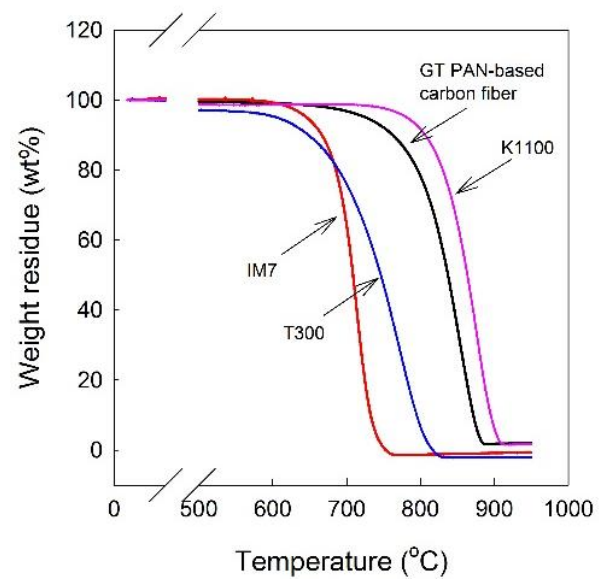

Fig. 5 - Oxidative thermal degradation behavior of the GT PAN based carbon fiber. The degradation behavior of IM7, T300, and K1100 carbon fibers is also given for comparison. The heating rate was $10{ }^{\circ} \mathrm{C} / \mathrm{min}$ and the air flow rate was $25 \mathrm{~mL} / \mathrm{min}$.

In order to understand the tensile modulus behavior of the GT PAN based carbon fiber, theoretical plots of the carbon fiber elastic modulus as a function of $\mathrm{FWHM}_{\mathrm{azi}, 002}$ are plotted for various $\mathrm{G}_{12}$ values in Fig. $3 e[10,25] . \mathrm{G}_{12}$ is shear modulus between graphitic planes. For perfect graphite, the value of $\mathrm{G}_{12}$ is $4 \mathrm{GPa}$ [10]. The modulus value for near perfect graphitic fiber $\mathrm{K} 1100$ falls on the line represented by $\mathrm{G}_{12}=4 \mathrm{GPa}$ as expected, while the data for T300, IM7, and GT PAN carbon fibers fall on the line represented by the $\mathrm{G}_{12}$ value of $30 \mathrm{GPa}$. The higher modulus PAN based carbon fiber M60JB falls in between the lines represented by $\mathrm{G}_{12}$ of 10 and $20 \mathrm{GPa}$. Thus, the inter-planar shear modulus in high strength PAN based carbon fibers is 30 
$\mathrm{GPa}$, while in graphite the value is only $4 \mathrm{GPa}$, and falls between these two values for other carbon fibers.

\section{Conclusion}

This study showed that gel spinning of PAN can result in carbon fibers with a combination of high tensile strength and tensile modulus that has not been achieved previously. In this context, it should also be noted that the current performance of solution spun PAN based carbon fibers has been achieved after nearly half a century of materials and process optimization. However, very limited material and process optimization studies have been carried out to date on the gel spun PAN fiber. Therefore, the gel spun PAN based carbon fiber properties reported in this paper should be considered as the baseline values for this process. Materials and process optimization, enhanced fiber circularity, and increased solution homogeneity will further increase the strength and modulus beyond those reported in this study.

\section{Acknowledgments}

This study was supported by DARPA, Army Research Office (grant number W911NF10-1-0098), and the Air Force Office of Scientific Research (grant number FA9550-14-1-0194).

\section{References}

[1] Masson JC. Acrylic Fiber Technology and Applications. New York: Marcel Dekker, Inc; 1995.

[2] Donnet J-B, Wang TK, Rebouillat S, Peng JCM. Carbon Fibers. New York: Marcel Dekker; 1998.

[3] Peebles LH. Carbon Fibers - Formation, Structure, and Properties. Boca Raton: CRC Press; 1995.

[4] Minus ML, Kumar S. The processing, properties, and structure of carbon fibers. JOM. 2005;57(2):52-8.

[5] Toray. Torayca Data Sheet. 2014 [cited February 2012]; Available from: http://www.torayca.com/en/properties/report_eng01_2.html 
[6] Hexcel. HexTow Carbon Fiber Product Data. 2014 [cited February 2012]; Available from: http://www.hexcel.com/resources/cont-carbon-fiber-data-sheets

[7] Toray. Carbon fiber composite materials. 2014 [cited 2014 March 10]; Available from: http://cs2.toray.co.jp/news/toray/en/newsrrs02.nsf/0/B126D9D8433675EE49257D11001 $\underline{770 \mathrm{C} 5}$

[8] Dumitrica T, Hua M, Yakobson BI. Symmetry-, time-, and temperature-dependent strength of carbon nanotubes. Proc Natl Acad Sci U S A. 2006;103(16):6105-9.

[9] Kelly A, Macmillan NH. Strong Solids. New York: Oxford University Press; 1986.

[10] Johnson W. The structure of PAN based carbon fibers and relationship to the physical properties. New York: Elsevier Science Publisher; 1988.

[11] Gupta VB, Kothari VK. Manufactured Fibre Technology. New York: Chapman \& Hall; 1997.

[12] Smith P, Lemstra PJ. Ultra-high-strength polyethylene filaments by solution spinningdrawing. Journal of Materials Science. 1980;15(2):505-14.

[13] Chae HG, Minus ML, Rasheed A, Kumar S. Stabilization and carbonization of gel spun polyacrylonitrile/single wall carbon nanotube composite fibers. Polymer. 2007;48(13):3781-9.

[14] Liu Y, Chae HG, Kumar S. Gel-spun carbon nanotubes/polyacrylonitrile composite fibers. Part III: Effect of stabilization conditions on carbon fiber properties. Carbon. 2011;49(13):4487-96.

[15] Şahin K, Fasanella NA, Chasiotis I, Lyons KM, Newcomb BA, Kamath MG, et al. High strength micron size carbon fibers from polyacrylonitrile-carbon nanotube precursors. Carbon. 2014;77(0):442-53.

[16] Chae HG, Sreekumar TV, Uchida T, Kumar S. A comparison of reinforcement efficiency of various types of carbon nanotubes in polyacrylonitrile fiber. Polymer. 2005;46(24):10925-35.

[17] Tan L, Liu S, Song K, Chen H, Pan D. Gel-spun polyacrylonitrile fiber from pregelled spinning solution. Polymer Engineering \& Science. 2010;50(7):1290-4.

[18] Sen K, Bahrami SH, Bajaj P. High-Performance Acrylic Fibers. Journal of Macromolecular Science, Part C. 1996;36(1):1-76. 
[19] Lyons KM, Newcomb BA, Mcdonald KJ, Chae HG, Kumar S. Development of single filament testing procedure for polyacrylonitrile precursor and polyacrylonitrile-based carbon fibers. Journal of Composite Materials. 2014; September 1. DOI 10.1177/0021998314545184.

[20] Adams PM, Katzman HA, Rellick GS, Stupian GW. Characterization of high thermal conductivity carbon fibers and a self-reinforced graphite panel. Carbon. 1998;36(3):23345.

[21] Warner SB, Peebles LH, Uhlmann DR. Oxidative stabilization of acrylic fibers .1. Oxygen-uptake and general-model. Journal of Materials Science. 1979;14(3):556-64.

[22] Whitney W, Kimmel RM. Griffith equation and carbon fiber strength. Nature-Physical Science. 1972;237(75):93-4.

[23] Reynolds WN, Sharp JV. Crystal shear limit to carbon-fiber strength. Carbon. 1974;12(2):103-10.

[24] Chae HG, Kumar S. Materials science - Making strong fibers. Science. 2008;319(5865):908-9.

[25] Liu T, Kumar S. Effect of orientation on the modulus of SWNT films and fibers. Nano Letters. 2003;3(5):647-50.

[26] Han CD, Jhon MS. Correlations of the 1st normal stress difference with shear-stress and of the storage modulus with loss modulus for homopolymers. Journal of Applied Polymer Science. 1986;32(3):3809-40.

[27] Naito K, Yang JM, Tanaka Y, Kagawa Y. The effect of gauge length on tensile strength and Weibull modulus of polyacrylonitrile (PAN)- and pitch-based carbon fibers. Journal of Materials Science. 2012;47(2):632-42.

[28] Shioya M, Inoue H, Sugimoto Y. Reduction in tensile strength of polyacrylonitrile-based carbon fibers in liquids and its application to defect analysis. Carbon. 2013;65:63-70. 